\title{
Betting Against Beta in the Indian Market
}

\author{
Sobhesh Kumar Agarwalla, Joshy Jacob, Jayanth R. Varma \& \\ Ellapulli Vasudevan
}

W.P. No. 2014-07-01

July 2014

The main objective of the Working Paper series of IIMA is to help faculty members, research staff, and doctoral students to speedily share their research findings with professional colleagues and to test out their research findings at the pre-publication stage.

\section{INDIAN INSTITUTE OF MANAGEMENT \\ AHMEDABAD - 380015 \\ INDIA}




\title{
Betting Against Beta in the Indian Market \\ Sobhesh Kumar Agarwalla, Joshy Jacob*, Jayanth R. Varma \& Ellapulli Vasudevan
}

\begin{abstract}
Recent empirical evidence from different markets suggests that the security market line is flatter than posited by CAPM. This flatness implies that a portfolio long in low-beta assets and short in high-beta assets would earn positive returns. Frazzini and Pedersen (2014) conceptualize a $\mathrm{BAB}$ factor that tracks such a portfolio. We find that a similar BAB factor earns significant positive returns in India. The returns on the $\mathrm{BAB}$ factor dominate the returns on the size, value and momentum factors. We also find that stocks with higher volatility earn relatively lower returns. These findings indicate overweighting of riskier assets by leverage constrained investors in the Indian market.
\end{abstract}

Key words: CAPM, Betting against beta, BAB factor, leverage constraint, emerging markets JEL classifications: G11, G12, G14, G15

${ }^{*}$ Corresponding author. Faculty member, Indian Institute of Management Ahmedabad, Vastrapur, Ahmedabad, Gujarat, India - 380015. All authors have contributed equally to the paper. The authors can be contacted at: sobhesh@iimahd.ernet.in, joshyjacob@iimahd.ernet.in, jrvarma@iimahd.ernet.in \& ev.vasu@gmail.com. 


\section{Introduction}

The Sharpe-Lintner version of the capital asset pricing model (CAPM) predicts that the expected return on assets would increase with their systematic risk, measured by the beta. However, empirical evidence from different markets suggest a much flatter relation between beta and returns. Black (1972) showed that various borrowing constraints, including margin requirements, could lead to the flatness. Black suggested that one of the factors that contributes to the flatness of the security market line is overweighting of the high-beta assets by leverage constrained investors. ${ }^{\dagger}$ Black (1993) argued that a factor which involves shorting of the high-beta assets and being long on the low-beta assets would be priced in the market. He examined the returns to such a beta factor and found that it generated significant positive returns in excess of its risk. He also found that the beta factor earned greater returns than both the size and book-to-market factors. He further argued that "Beta is a valuable tool if the line is as steep as the CAPM predicts. It is even more valuable if the line is flat." These evidences suggest that the Sharpe-Lintner-Black model of CAPM with borrowing constraints would be a better fit of the empirical return data.

Recently, Frazzini and Pedersen (2014) re-examine this issue in a richer theoretical and empirical context and document pervasive evidence of low returns generated by the high-beta assets. They model investors with leverage and margin constraints and examine the implications for the pricing of beta. More specifically, they model a market with different types of agents (a) agents who cannot leverage and overweight the high-beta assets (b) agents who can leverage but face margin constraints and underweight the high-beta assets, and (c) agents who are unconstrained and lever up the lowbeta assets. The model produces a flatter security market line as in Black (1972). The specific propositions of the model are as follows (i) the slope of the security market line would depend on the tightness of the funding constraints across agents (ii) during times of tightening funding constraints, agents de-leverage and therefore the high-beta stocks earn lower returns (iii) when funding liquidity risk is high, betas in the cross-section are compressed towards one, and (iv) more constrained investors overweight the high-beta assets and less constrained investors underweight the high-beta assets. They develop a beta factor in the lines of Black (1993), called the "Betting against beta" factor (BAB factor). They find that the $\mathrm{BAB}$ factor earns significant returns using data from 20 international equity markets, treasury bond markets, credit markets, and futures markets. Their empirical evidence suggests that the relative flatness of the security market line is widespread in the

\footnotetext{
†The other reason for the flatness suggested by Black (1972) is the use of inappropriate market proxy
} 
world. Their BAB factor returns are also robust to variations in firm size and idiosyncratic risk. They find that more leverage constrained investors hold high-beta portfolios and the less constrained ones hold low-beta portfolios.

We examine the return dynamics of the high-beta and low-beta assets in the Indian market. The flatness of the security market line in India has also been documented (for instance, Ansari, 2000). The Indian market could provide interesting insights into the impact of financing constraints on the risk-return dynamics for a variety of reasons. First, the emerging markets have severe financing constraints relative to the markets examined in Frazzini and Pedersen (2014). Second, unlike most other markets, India has a very active single stock futures market. This could offer significant leverage opportunity to investors in stocks with active derivative markets. These features would afford a closer examination of the impact of leverage constraints on the pricing of beta and the overall risk-return relation.

Our key findings are as follows. First, the BAB factor earns significant positive returns in the Indian market. Second, the returns of the BAB factor dominates the return of the size, value and momentum factors in India. Third, we also find that the stocks with higher volatility earn relatively lower returns. These findings indicate overweighting of riskier assets by leverage constrained investors in the Indian market.

The reminder of the paper is organised as follows. Section 2 describes the data used in the analysis and Section 3 details the approach used in the analysis. Section 4 discusses our key findings on the pricing of the beta factor and Section 5 concludes.

\section{Data}

We include all the stocks traded in the Bombay Stock Exchange (BSE) ever since January 1993 in the analysis. The required data is taken from the Prowess database maintained by the Centre for Monitoring Indian Economy (CMIE). While the return data of the stocks are available from January 1990 the risk-free returns are available only from January 1993. Hence, we limit the analysis to the 20.5 years period between January 1993 and June 2013. The returns on the Fama-French factors (Fama and French, 1992) and momentum (Jegadeesh and Titman, 1993) are taken from the data 
library of the recent paper on systematic risk factors in India by Agarwalla et al. (2013). The riskfree returns, measured as the yield on the 91-day treasury bills, are taken from the Reserve Bank of India website. ${ }^{\ddagger}$ Sensex, the popular market-value weighted index of the 30 largest stocks in India, is used as the market proxy. ${ }^{\S}$

The summary statistics of the data is given in Table 1 . There is a significant increase in the number of traded firms and the market capitalization over the period of analysis. On an average about 3,500 firms trade in the market. The aggregate market capitalization ranges from ₹2.4 trillion in 1993 to ₹66.1 trillion in 2013. The average market risk premium based on Sensex is about 8\% per annum. The distribution of the market capitalization of the firms suggest that $90 \%$ of the firms can be regarded as small firms as their average market capitalisation over time is below ₹8 million.

\section{Methodology}

The pre-ranking stock betas are estimated with five-years daily stock returns and Sensex returns. We adopt the following approach for beta estimation.

$$
\beta_{i t}=\rho_{i t} \frac{\sigma_{i t}}{\sigma_{m t}}
$$

where we estimate the $\rho_{i t}$, the correlation between the market and stock, based on three-day cumulative excess returns over a period of five years to handle the possible influence of non-synchronous trading. The stock volatility $\left(\sigma_{i t}\right)$ and the market market volatility $\left(\sigma_{m t}\right)$ are estimated as the standard deviation of the daily excess returns over one-year period. The use of returns over a longer period for the estimation of correlation is in line with the evidence of slowly evolving correlations. To estimate the volatility the stocks should have traded for at least 120 days in the last one-year. Similarly, to estimate the correlation the stocks should have traded for at least 750 days during the last five years.

It is well-known that regression betas are subject to estimation error (S.E. of beta). Hence, it is common in event studies and IPO literature to assume a $\beta$ of one (equal to market beta) for stocks, as regression estimates are either unreliable or impossible. However, the market beta estimate also has an error equal to the cross-sectional variation of the betas around the mean of 1 . Vasicek (1973)

\footnotetext{
$\ddagger_{\text {http://dbie.rbi.org.in/DBIE/dbie.rbi?site=statistics }}$

$\S$ It is an index maintained by the Bombay Stock Exchange.
} 
developed a shrinkage beta estimator to combine the market beta and the stock beta in attempt to improve the reliability of stock betas. This beta estimator is a weighted average of the two betas as given by Equation 2 and is regarded as the statistically optimal estimator.

$$
\beta_{i}^{s}=\beta_{i} w_{i}+\beta_{m}\left(1-w_{i}\right)
$$

where $\beta_{i}^{s}$ is the shrunk stock beta, $\beta_{m}$ the market beta, and $\beta_{i}$ the stock beta, estimated with Equation 1. The weight $w_{i}$ of each stock is estimated as below.

$$
w_{i}=\frac{1}{T} \sum_{t=1}^{T} \frac{\sigma_{\beta_{t}}^{2}}{\mathrm{~S} . \mathrm{E} \beta_{i t}+\sigma_{\beta_{t}}^{2}}
$$

where $\sigma_{\beta_{t}}^{2}$ is the cross-sectional variation in the betas at time $t$, and S.E $\beta_{i t}$ is the standard error of the beta estimate of stock $i$ at time $t$, estimated through regression of the daily stock returns on the market returns using five years rolling returns.

Equation 2 requires $w_{i}$ to be estimated separately for each stock. The $w_{i}$ in our dataset varies from 0.6 to 0.85 and has a pooled average of 0.7 . However, for simplicity and robustness, it is common in the literature to use a single value of $w_{i}$ for all the stocks. We take $w_{i}$ equal to 0.6 following Frazzini and Pedersen (2014) and Vasicek (1973). Alternative choices like, $w_{i}=0.7$ (the pooled average of estimated $\left.w_{i}\right)$, do not make any material difference to our results.

There are many instances in the Indian market where very large market capitalization firms, which account for a large share of the total market value, are listed through IPOs (primarily disinvestment of public sector firms). We would not be able to include such large market cap firms in the analysis for a very long period as reliable beta estimation with Equation 1 requires a minimum of five years return data. Therefore, we attempt to include them in the analysis starting from the second year of their trading by downwardly adjusting the weight given to their betas in Equation 2. This adjustment is done using the relationship between the standard error (SE Beta it in this case) and sample size. This adjustment leads to the following stock beta estimate, when the return data for a newly listed stock is not available for 5 years (proof given in Appendix A). 


$$
\beta_{i N}^{s}=\frac{40}{40+N} \times \beta_{m}+\frac{N}{40+N} \times \beta_{i N}
$$

where $\beta_{i N}^{s}$ is the shrinkage beta estimated at the end of month $N, \beta_{m}$ is the market beta (equal to 1) and $\beta_{i N}$ is the stock beta estimated with Equation 1. $N$ takes value between 13 (corresponding to the first month in the second year of trading) and 60 .

We follow the methodology of Frazzini and Pedersen (2014) to construct the long-short beta portfolios and to estimate the $\mathrm{BAB}$ factor returns as their approach makes the portfolio both market neutral and self-financing. For each month $t$, the stocks are divided into two groups (portfolios) based on their beta values at $t-1$. The portfolio above (below) the median is called the high-beta (low-beta) portfolio. The BAB factor returns $\left(B A B_{t}\right)$ are estimated as below.

$$
B A B_{t}=\frac{1}{\bar{\beta}_{L}}\left(\bar{R}_{L, t}-R_{F, t}\right)-\frac{1}{\bar{\beta}_{H}}\left(\bar{R}_{H, t}-R_{F, t}\right)
$$

where $\bar{\beta}_{L}\left(\bar{\beta}_{H}\right)$ is the weighted average beta of the low- $\beta$ (high- $\beta$ ) portfolios. $\bar{R}_{L, t}\left(\bar{R}_{H, t}\right)$ is the weighted returns on the low- $\beta$ (high- $\beta$ ) portfolio. $R_{F, t}$ is the risk-free returns measured as the yield on the 91-day treasury bills. The weights are determined based on the beta ranks of the stocks in the portfolio. For every month $t$ in our estimation period, the weight assigned to the return of each stock, $W_{i}$, is estimated as follows.

$$
W_{i}=\frac{2 \times\left|\operatorname{Rank}_{i}-\overline{\operatorname{Rank}}\right|}{\sum_{i=1}^{n}\left|\operatorname{Rank}_{i}-\overline{\operatorname{Rank}}\right|}
$$

$\operatorname{Rank}_{i}$ is the $\beta$-rank of stock $i$ among all the $n$ (including both high-beta and low-beta) stocks included at time period $t-1 . \overline{R a n k}$ is the mean rank. This weighting tilts the high- $\beta$ (low- $\beta$ ) portfolio towards stocks with the highest (lowest) betas. The portfolios are reconstituted every month based on the beta values in the immediately prior month.

The performance of the BAB factor and of various beta-ranked portfolios are examined through calender-time regressions of the portfolio excess returns using the CAPM, 3-factor and 4-factor models as follows: 


$$
R_{i t}^{e}=\alpha_{i}+\sum_{k=1}^{n} \beta_{i} R_{k t}+e_{i t}
$$

where $R_{i t}^{e}$ is the excess-return on portfolio $i$ during period $t, R_{k t}$ is the factor return during the same period and $n$ is the number of factors (for instance, three in the Fama-French model).

Even though we attempt to estimate beta of individual stocks with less than five years of return data using Equation 4, we avoid this approach in the initial five years of our sample (January 1993 - December 1997), as all the stocks would then require this adjustment. Hence, the BAB factor returns are estimated only for a period of 15.5 years from January 1998 to June 2013.

\section{Findings and discussion}

\subsection{Beta characteristics}

We observe that the high-beta stocks are relatively larger, more volatile and have high book-tomarket ratios in the Indian market. The time series average of the market value weighted betas (0.97), estimated with Equation 2, is close to the market beta of one. ${ }^{\top}$ The effect of the shrinking of the stock betas towards the market beta (1.0) is more on the higher values of beta. The distribution of the shrunk betas over time is given in Figure 1. The distribution indicates that there is large cross-sectional variation in the betas of Indian firms. The distribution also exhibits significant time variation with a noticeable compression in the cross-sectional betas during certain periods. For instance, upper percentile of the betas significantly fall during year 2008, which is known to be a financially constrained period. On the other hand, the lower percentile betas exhibit lower variation over time. Similar behaviour of betas is documented by Frazzini and Pedersen (2014). They attribute the cross-sectional compression of the betas to funding constraints in the market.

\subsection{Beta-sorted portfolio returns}

The return and other characteristics of the portfolios formed on their pre-ranking betas are given in Table 2. The realized betas almost fully follow the rank-order of their pre-ranking betas. The excess returns, Sharpe ratios and the alphas of the 10 beta-decile portfolios decrease more or less monotonically with their ex-ante betas. For instance, the monthly CAPM alpha of the high-beta

\footnotetext{
I The weighted betas are not strictly equal to the market beta of one as the market proxy, Sensex, does not include all the traded stocks.
} 
(P10) portfolio is $-2.89 \%$ as compared to $-0.44 \%$ of the low-beta portfolio, when equally-weighted portfolio returns are used. The alphas of the beta-deciles are negative in the Indian market due to the poor performance of a large number of small stocks in all the portfolios. In fact, only about $20 \%$ of the stocks earn positive excess returns in the Indian market, which are primarily large stocks. This is reflected in the positive returns and alphas of several of the portfolios when market value weighted returns, as given in Panel B of Table 2. In fact, all the alphas turn less negative with market value weighted returns. Alphas estimated with calender-time regressions of the portfolio returns with 3- and 4-factor models also exhibit similar trend. All the 3- and 4-factor alphas are negative and statistically significant for the higher beta portfolios (P8 - P10).

\subsection{Returns to the market-neutral BAB factor}

Table 2 also gives the returns on the market-neutral BAB factor. As expected in a market-neutral portfolio, the realized beta of the BAB factor is very close to zero (0.09). The BAB portfolio on an average is equivalent to a long position of ₹ 1.32 on the low-beta beta portfolio and a short position of ₹ 0.91 on the high-beta beta portfolio. The BAB factor earns statistically and economically significant returns as suggested by its alphas. For instance, it earns a monthly alpha of $1.08 \%$ relative to the 4-factor model. These findings are similar to the results of Frazzini and Pedersen (2014) for other markets.

The yearly $\mathrm{BAB}$ factor returns and its comparison with the size, value and momentum factor returns are given in Table 3. Overall, the BAB factor earns a positive return during the 15.5 year period (from January 1998 to June 2013) in the Indian market. For most of the years during the period the $\mathrm{BAB}$ factor earns greater return than the market risk premium. The average return suggests that the $\mathrm{BAB}$ factor dominates the size, value, and momentum factors in the Indian market. For instance, the most dominant among the 4 -factors, momentum, earns an average return of $22.3 \%$ compared to $29.1 \%$ of the $\mathrm{BAB}$ factor. The relative economic significance of the BAB factor returns is also reflected in Figure 2 which plots the cumulative returns of the different factors.

Overall these findings strongly suggest that there is significant overweighting of high-beta assets in the Indian market, due to leverage constraints and funding liquidity risk faced by certain investor categories. Further, the significant time-variation of the BAB factor returns is most likely to be 
linked to the time-variation of funding constraints in the Indian market.

We also examine the robustness the BAB factor returns to various anomalies including, size, value, momentum and volatility.

\subsection{Robustness with size, value and momentum}

The robustness of the $\mathrm{BAB}$ factor returns are examined by re-estimating the $\mathrm{BAB}$ returns on various sub-portfolios sorted on size, value and momentum. Accordingly, the stocks are classified into standardized groups like Value and Growth (based on B/M), Small and Big (based on size) and Winner and Loser (based on momentum). The excess returns and the 4-factor alphas of each of these sub-portfolios are given in Table 4. The excess returns and the alphas are positive in all the cases. As given in Panel A of the table, the BAB factor return is greater in the case of small stocks. On the value dimension, it appears that the $\mathrm{BAB}$ factor does not have a statistically significant alpha for the growth firms. The BAB factor alphas are not statistically significant for both the Winner and Loser stocks.

\subsection{Beta factor returns and volatility}

We find a positive correlation of 0.34 between the beta and the total volatility of stocks in the Indian market. Given this positive correlation, the BAB factor is likely to be related to the volatility anomaly (Ang et al., 2006, 2009; Baker et al., 2011). We carry out a preliminary analysis of the relation between total volatility and returns. We find that the low-volatility portfolios earn positive alphas and high-volatility portfolios earn negative alphas (as given in Table 5), particularly in the case of smaller stocks (Table 6). Even within different size groups of firms, the volatility anomaly prevails. The possible link between the $\mathrm{BAB}$ factor and the volatility anomaly in the Indian context is being examined by the authors.

\section{Conclusion}

We examine the return dynamics of the high-beta and the low-beta stocks in the Indian market. The relatively higher funding constraints and its significant time variation in the Indian market, creates an ideal setting to bring out the nature of interactions between financing constraints, margin requirements and the pricing of beta. We find that the market-neutral long-short portfolio (BAB 
factor), conceptualized by Frazzini and Pedersen (2014), earns significant positive returns in the Indian market. The returns of this factor dominate the size, value, and momentum factors returns in India. The overall results overweighting of the high-beta assets by leverage constrained investors in the Indian market. The authors are currently engaged in extending this research to understand the possible linkage between the BAB factor pricing and financial constraints in the Indian market. 


\section{References}

Agarwalla, S. K., Jacob, J., and Varma, J. R. (2013). Four factor model in Indian equities market. Working Paper W.P. No. 2013-09-05, Indian Institute of Management, Ahmedabad.

Ang, A., Hodrick, R. J., Xing, Y., and Zhang, X. (2006). The cross-section of volatility and expected returns. The Journal of Finance, 61(1):259-299.

Ang, A., Hodrick, R. J., Xing, Y., and Zhang, X. (2009). High idiosyncratic volatility and low returns: International and further us evidence. Journal of Financial Economics, 91(1):1-23.

Ansari, V. A. (2000). Capital asset pricing model: should we stop using it? Vikalpa, 25(1):55-64.

Baker, M., Bradley, B., and Wurgler, J. (2011). Benchmarks as limits to arbitrage: Understanding the low-volatility anomaly. Financial Analysts Journal, 67(1).

Black, F. (1972). Capital market equilibrium with restricted borrowing. Journal of business, pages $444-455$.

Black, F. (1993). Beta and return. Streetwise: The Best of the Journal of Portfolio Management, page 74 .

Fama, E. F. and French, K. R. (1992). The cross-section of expected stock returns. the Journal of Finance, 47(2):427-465.

Frazzini, A. and Pedersen, L. H. (2014). Betting against beta. Journal of Financial Economics, 111(1):1-25.

Jegadeesh, N. and Titman, S. (1993). Returns to buying winners and selling losers: Implications for stock market efficiency. The Journal of Finance, 48(1):65-91.

Vasicek, O. A. (1973). A note on using cross-sectional information in bayesian estimation of security betas. The Journal of Finance, 28(5):1233-1239. 


\section{A Beta Shrinkage Estimator}

\section{A.1 Basic Bayesian Model}

$$
\beta^{\text {Shrunk }}=\frac{H^{\text {Prior }}}{H^{\text {Prior }}+H^{\text {Regression }}} \times \beta^{\text {Prior }}+\frac{H^{\text {Regression }}}{H^{\text {Prior }}+H^{\text {Regression }}} \times \beta^{\text {Regression }}
$$

where $H^{\text {Prior }}=\frac{1}{\sigma_{\text {Prior }}^{2}}$ is the precision of the prior (cross-sectional estimate)

$H^{\text {Regression }}=\frac{1}{\sigma_{\text {Regression }}^{2}}$ is the precision of the regression (sample) and $\beta^{\text {Prior }}=1$

\section{A.2 Ratio of the Precisions in the Vasicek Model}

In the Vasicek (1973) estimate, the regression estimate is based on 60 months and $\frac{H^{\text {Prior }}}{H^{\text {Prior }}+H^{\text {Regression: } 60}}=0.4$

$\frac{H^{\text {Regression: } 60}}{H^{\text {Prior }}+H^{\text {Regression: } 60}}=0.6$

$$
\beta^{\text {Shrunk }}=0.4 \times \beta^{\text {Prior }}+0.6 \times \beta^{\text {Regression }}
$$

The ratio of $H^{\text {Prior }}$ and $H^{\text {Regression:60 }}$ is computed as follows:

$$
\begin{aligned}
& \frac{H^{\text {Prior }}}{H^{\text {Prior }}+H^{\text {Regression: } 60}}=0.4 \\
& \Rightarrow H^{\text {Prior }}=0.4 \times H^{\text {Prior }}+0.4 \times H^{\text {Regression: } 60} \\
& \Rightarrow 0.6 H^{\text {Prior }}=0.4 \times H^{\text {Regression: } 60} \\
& \Rightarrow 1.5 H^{\text {Prior }}=H^{\text {Regression: } 60}
\end{aligned}
$$




\section{A.3 Modification for smaller sample size}

From basic sampling theory

$$
H^{\text {Regression: } N}=\frac{N}{60} H^{\text {Regression: } 60}=1.5 \frac{N}{60} H^{\text {Prior }}=\frac{N}{40} H^{\text {Prior }}
$$

As such

$$
\frac{H^{\text {Prior }}}{H^{\text {Prior }}+H^{\text {Regression: } N}}=\frac{1}{1+\frac{N}{40}}=\frac{40}{40+N}
$$

This yields the estimate

$$
\beta^{\text {Shrunk }}=\frac{40}{40+N} \times \beta^{\text {Prior }}+\frac{N}{40+N} \times \beta^{\text {Regression }: N}
$$

$\beta_{m}$ (market beta) is the efficient estimator of $\beta^{\text {Prior }}$. Hence the above equation becomes

$$
\beta_{i N}^{s}=\frac{40}{40+N} \times \beta_{m}+\frac{N}{40+N} \times \beta_{i N}
$$

where $\beta_{i N}^{s}$ is the shrinkage beta estimated at the end of month $N, \beta_{m}$ is the market beta (equal to 1 ) and $\beta_{i N}$ is the stock beta as estimated following Equation 1. $N$ takes value between 13 (first month in the second year of trading) and 60 . 
Figure 1: Beta percentile points over the time

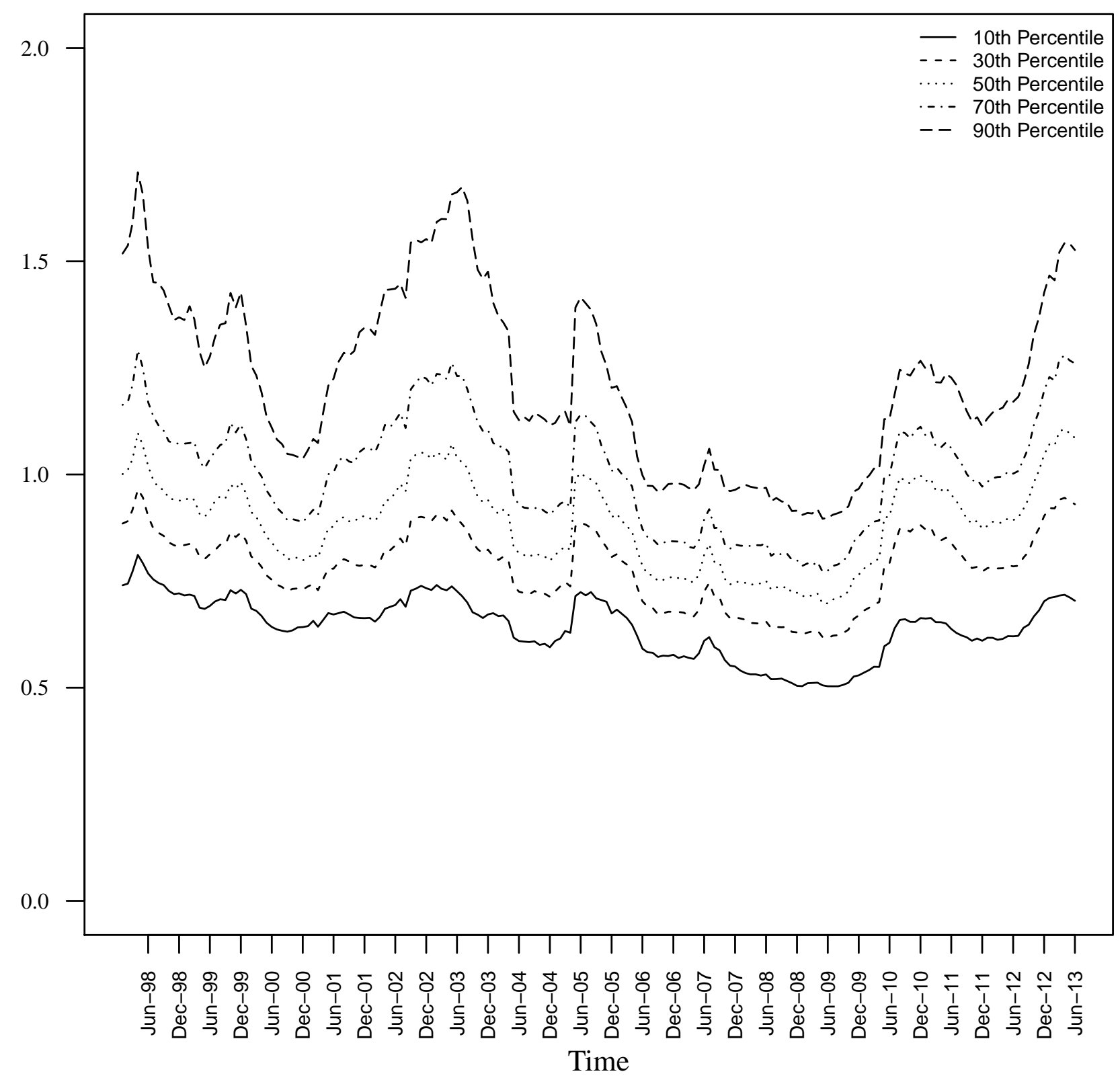




\section{Figure 2: Beta and four-factors over time}

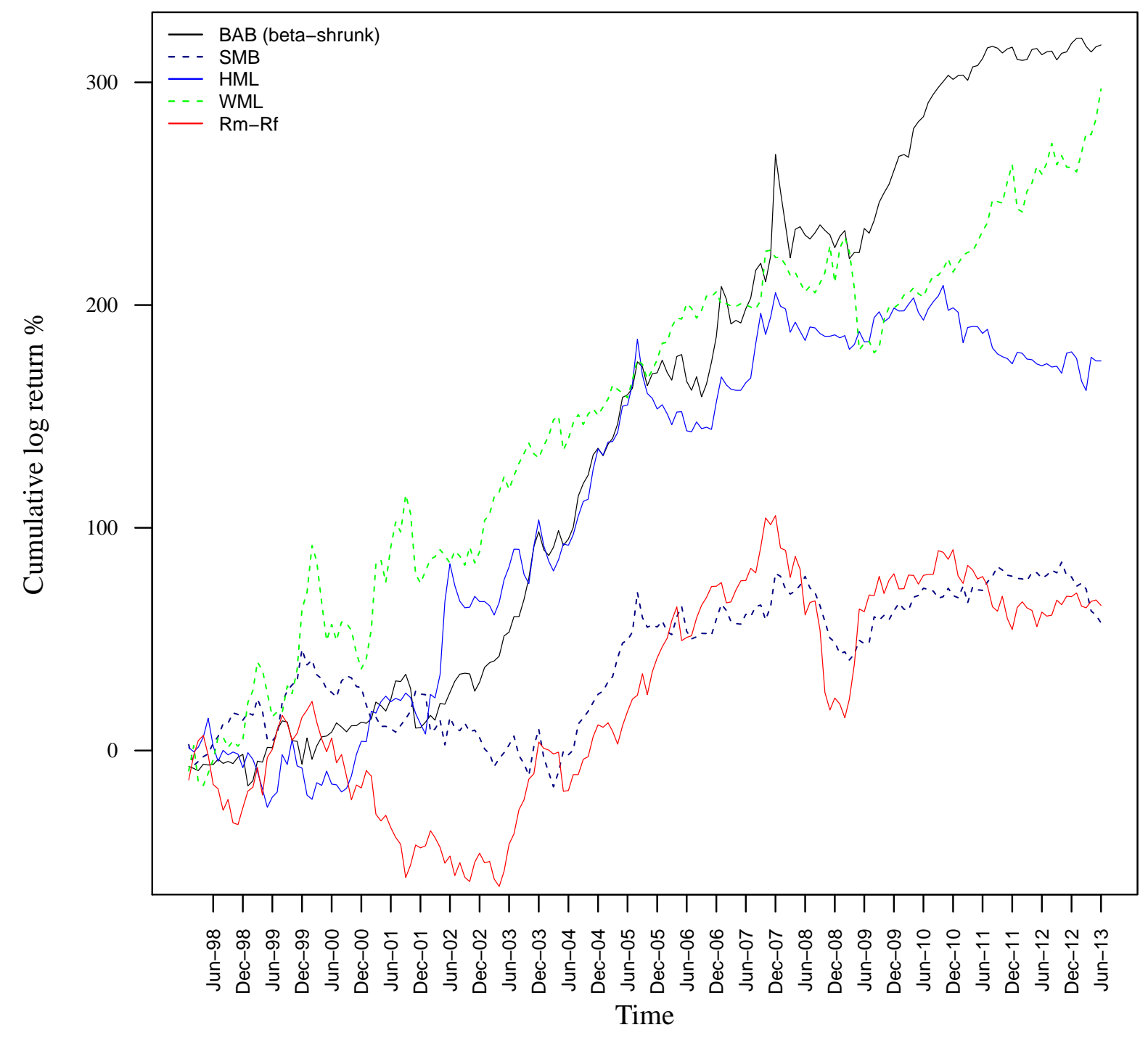

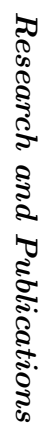


Table 1: Summary statistics of the data

\begin{tabular}{|c|c|c|c|c|c|c|c|c|}
\hline \multirow[t]{2}{*}{ Year } & \multirow[t]{2}{*}{$\begin{array}{l}\text { Number of } \\
\text { firms }\end{array}$} & \multicolumn{3}{|c|}{$\begin{array}{l}\text { Market cap. percentile (₹ } \\
\text { million) }\end{array}$} & \multirow{2}{*}{$\begin{array}{l}\text { Aggregate } \\
\text { market cap. (₹ } \\
\text { million) }\end{array}$} & \multirow{2}{*}{$\begin{array}{l}\text { Average } \\
\text { market cap. } \\
\text { (₹ million) }\end{array}$} & \multirow[t]{2}{*}{$\begin{array}{l}\text { Sensex } \\
\text { return }(\%)\end{array}$} & \multirow[t]{2}{*}{$\begin{array}{l}\text { Risk-free } \\
\text { return }(\%)\end{array}$} \\
\hline & & $10 \%$ & $50 \%$ & $90 \%$ & & & & \\
\hline 1993 & 2278 & 26 & 136 & 1,609 & $2,395,366$ & 1,052 & 27.94 & 9.16 \\
\hline 1994 & 3358 & 39 & 181 & 2,135 & $4,826,523$ & 1,437 & 17.36 & 8.36 \\
\hline 1995 & 4721 & 31 & 106 & 1,238 & $4,934,752$ & 1,045 & -20.79 & 12.08 \\
\hline 1996 & 5319 & 15 & 55 & 778 & $4,497,657$ & 846 & -0.81 & 10.99 \\
\hline 1997 & 4921 & 7 & 36 & 635 & $4,881,884$ & 992 & 18.60 & 7.10 \\
\hline 1998 & 4000 & 7 & 35 & 748 & $4,349,433$ & 1,087 & -16.50 & 7.98 \\
\hline 1999 & 3938 & 9 & 43 & 1,152 & $5,915,665$ & 1,502 & 63.83 & 9.09 \\
\hline 2000 & 3972 & 10 & 52 & 1,319 & $7,851,392$ & 1,977 & -20.65 & 9.03 \\
\hline 2001 & 3415 & 8 & 46 & 1,157 & $5,539,627$ & 1,622 & -17.87 & 7.47 \\
\hline 2002 & 3012 & 9 & 56 & 1,634 & $5,989,443$ & 1,989 & 3.52 & 6.04 \\
\hline 2003 & 2915 & 10 & 69 & 2,351 & $8,149,890$ & 2,796 & 72.89 & 4.94 \\
\hline 2004 & 2869 & 12 & 104 & 4,203 & $13,640,240$ & 4,754 & 13.08 & 4.68 \\
\hline 2005 & 2954 & 26 & 275 & 8,253 & $20,163,835$ & 6,826 & 42.33 & 5.38 \\
\hline 2006 & 2983 & 24 & 353 & 13,053 & $31,556,966$ & 10,579 & 46.70 & 6.35 \\
\hline 2007 & 3118 & 33 & 504 & 18,088 & $50,214,789$ & 16,105 & 47.15 & 7.15 \\
\hline 2008 & 3194 & 36 & 419 & 15,371 & $46,167,115$ & 14,454 & -52.45 & 7.88 \\
\hline 2009 & 3256 & 32 & 337 & 13,012 & $47,234,715$ & 14,507 & 81.03 & 3.65 \\
\hline 2010 & 3446 & 43 & 540 & 21,630 & $68,085,994$ & 19,758 & 17.43 & 5.37 \\
\hline 2011 & 3581 & 38 & 429 & 18,050 & $63,580,329$ & 17,755 & -24.64 & 7.88 \\
\hline 2012 & 3714 & 33 & 343 & 15,934 & $63,611,244$ & 17,127 & 25.70 & 8.44 \\
\hline 2013 & 3672 & 29 & 322 & 15,518 & $66,135,135$ & 18,011 & -0.32 & 7.82 \\
\hline
\end{tabular}

The table presents the year-wise market cap. percentiles, aggregate market cap., and the cross-sectional average of the market cap. of all the BSE listed firms. The yearly market cap. of a firm is the average of its month-end market cap. figures. The risk-free return is the yield on the 91-day Treasury bill. The 2013 period covers only the 6-months period from 1 January to 30 June. All the return figures are annualized. 
Table 2: Monthly alphas for various beta-deciles and the BAB factor

\begin{tabular}{|c|c|c|c|c|c|c|c|c|c|c|c|}
\hline Porfolio & $\begin{array}{c}\mathrm{P} 1 \\
(\text { Low-beta) }\end{array}$ & $\mathrm{P} 2$ & P3 & $\mathrm{P} 4$ & $\mathrm{P} 5$ & $\mathrm{P} 6$ & $\mathrm{P} 7$ & P8 & $\mathrm{P} 9$ & $\begin{array}{c}\text { P10 } \\
\text { (High-beta) }\end{array}$ & $\mathrm{BAB}$ \\
\hline \multicolumn{12}{|c|}{ Panel A: Equally weighted portfolios } \\
\hline $\mathrm{XR}\left(\right.$ over $R_{F}$ ) & 0.01 & 0.26 & 0.22 & 0.23 & -0.05 & 0.17 & -0.20 & -0.79 & -1.21 & -1.97 & $1.70^{* * *}$ \\
\hline CAPM alpha & -0.44 & -0.29 & -0.39 & -0.42 & $-0.72^{*}$ & -0.54 & $-0.96^{* *}$ & $-1.58 * * *$ & $-2.04^{* * *}$ & $-2.89 * * *$ & $1.67^{* * *}$ \\
\hline Three-factor alpha & $-0.99 * * *$ & $-0.79 * * *$ & $-0.89 * * *$ & $-0.92^{* * *}$ & $-1.20^{* * *}$ & $-1.10^{* * *}$ & $-1.50 * * *$ & $-2.16^{* * *}$ & $-2.68 * * *$ & $-3.61^{* * *}$ & $1.35^{* * *}$ \\
\hline Four-factor alpha & $-0.97 * * *$ & $-0.67^{* *}$ & $-0.79 * * *$ & $-0.73^{* * *}$ & $-1.00^{* * *}$ & $-0.89 * * *$ & $-1.25^{* * *}$ & $-1.78 * * *$ & $-2.32^{* * *}$ & $-3.09 * * *$ & $1.08^{* *}$ \\
\hline Beta (ex-ante) & 0.56 & 0.68 & 0.75 & 0.81 & 0.86 & 0.91 & 0.97 & 1.05 & 1.15 & 1.38 & 0.00 \\
\hline Beta (realized) & 0.70 & 0.86 & 0.96 & 1.01 & 1.05 & 1.12 & 1.18 & 1.24 & 1.31 & 1.44 & 0.09 \\
\hline Volatility & 31.43 & 33.37 & 34.37 & 35.70 & 36.32 & 38.94 & 40.88 & 43.51 & 47.20 & 54.71 & 23.79 \\
\hline Sharpe ratio & 0.00 & 0.09 & 0.08 & 0.08 & -0.02 & 0.05 & -0.06 & -0.22 & -0.31 & -0.43 & 0.86 \\
\hline \multicolumn{12}{|c|}{ Panel B: Market value weighted portfolios } \\
\hline $\mathrm{XR}\left(\right.$ over $\left.R_{F}\right)$ & 0.31 & 0.56 & $0.85^{*}$ & $0.79 *$ & 0.11 & 0.42 & 0.13 & -0.42 & -0.44 & -1.19 & $1.70^{* * *}$ \\
\hline CAPM alpha & -0.17 & 0.15 & 0.32 & 0.28 & -0.45 & -0.24 & -0.45 & $-1.11^{* * *}$ & $-1.11^{* * *}$ & $-2.01^{* * *}$ & $1.67^{* * *}$ \\
\hline Three-factor alpha & -0.32 & 0.05 & 0.28 & 0.26 & -0.47 & -0.35 & $-0.49^{*}$ & $-1.12^{* * *}$ & $-1.24^{* * *}$ & $-2.22 * * *$ & $1.35^{* * *}$ \\
\hline Four-factor alpha & -0.55 & 0.01 & 0.13 & 0.05 & $-0.57^{*}$ & -0.30 & -0.47 & $-1.19^{* * *}$ & $-0.86^{* *}$ & $-1.68 * * *$ & $1.08^{* *}$ \\
\hline Beta (ex-ante) & 0.56 & 0.68 & 0.75 & 0.81 & 0.86 & 0.91 & 0.97 & 1.05 & 1.15 & 1.38 & 0.00 \\
\hline Beta (realized) & 0.75 & 0.64 & 0.82 & 0.80 & 0.88 & 1.04 & 0.92 & 1.08 & 1.05 & 1.29 & 0.09 \\
\hline Volatility & 30.73 & 24.62 & 28.36 & 28.76 & 29.40 & 33.63 & 30.01 & 35.91 & 35.81 & 45.77 & 23.79 \\
\hline Sharpe ratio & 0.12 & 0.27 & 0.36 & 0.33 & 0.05 & 0.15 & 0.05 & -0.14 & -0.15 & -0.31 & 0.86 \\
\hline
\end{tabular}

P1 to P10 are the equally weighted (Panel A) or value weighted (Panel B) portfolios constructed based on the beta-deciles. Excess returns (XR) are calculated over the risk-free rate. Alpha is the intercept of the regression of the monthly portfolio excess return on the factors: (a) Market risk premium $\left(R_{M}-R_{F}\right)$ (b) $S M B$ (c) $H M L$ and (d) $W M L$. Portfolio premium is calculated as the excess return over the risk-free rate. Monthly alphas are percentage returns. Beta (ex-ante) is the average beta estimated with Equation 2 and Beta (realized) is estimated from the regressions of the realized returns. Volatility (\%) and Sharpe ratio are annualized figures. 
Table 3: BAB, Market, HML, SMB \& WML factor returns over the years

\begin{tabular}{lrrrrr}
\hline Calender year & $B A B(\%)$ & $R_{m}-R_{f}(\%)$ & $S M B(\%)$ & $H M L(\%)$ & $W M L(\%)$ \\
\hline 1998 & -1.71 & -22.66 & 14.57 & -7.41 & 4.96 \\
1999 & -4.30 & 50.18 & 37.51 & -0.18 & 79.84 \\
2000 & 20.74 & -27.22 & -15.82 & 12.78 & -23.57 \\
2001 & -2.46 & -23.58 & -2.87 & 8.20 & 47.02 \\
2002 & 22.68 & -2.37 & -17.80 & 73.07 & 15.08 \\
2003 & 96.60 & 64.75 & 3.98 & 44.29 & 52.33 \\
2004 & 45.43 & 8.02 & 16.91 & 37.56 & 21.15 \\
2005 & 40.28 & 35.06 & 35.27 & 19.61 & 28.35 \\
2006 & 17.73 & 37.94 & 3.56 & 3.20 & 35.67 \\
2007 & 126.42 & 37.33 & 22.84 & 63.31 & 16.68 \\
2008 & -34.21 & -55.92 & -26.55 & -17.22 & -10.61 \\
2009 & 41.37 & 74.66 & 15.18 & 12.78 & -10.82 \\
2010 & 50.62 & 11.45 & 7.00 & 0.11 & 17.45 \\
2011 & 15.59 & -30.15 & 9.07 & -22.23 & 62.03 \\
2012 & 1.71 & 15.91 & -0.32 & 5.52 & -1.26 \\
2013 & -0.74 & -3.85 & -18.64 & -4.01 & 42.26 \\
\hline Average & 29.10 & 11.56 & 6.84 & 15.56 & 22.29 \\
Volatility & 40.77 & 38.40 & 18.21 & 27.71 & 29.11 \\
\hline
\end{tabular}

All the given return figures are annualized percentage returns. The BAB factor returns are estimated based on Equation 5. The four factor returns taken from Agarwalla et al. (2013). The values for 2013 are only for the initial 6-months. The Average and Volatility figures exclude the 2013 data. 
Table 4: Robustness of BAB Factor returns with Size, B/M \& Momentum factors

\begin{tabular}{llclrrr}
\hline Portfolio & $\begin{array}{l}\text { Excess } \\
\text { return }\end{array}$ & t-value & $4 \mathrm{~F}-\alpha$ & $t$-value & Volatility & Sharpe ratio \\
\hline \multicolumn{7}{c}{ Panel A: Size } \\
\hline Small firms (deciles 1 - 9) & $0.24^{* * *}$ & 2.74 & $0.21^{* *}$ & 2.31 & 1.20 & 0.20 \\
Big firms (decile 10) & 0.14 & 0.74 & 0.30 & 1.62 & 2.58 & 0.05 \\
\hline \multicolumn{7}{c}{ Panel B: B/M } \\
\hline Growth firms (deciles 1 - 3) & 0.18 & 1.35 & 0.17 & 1.26 & 1.81 & 0.10 \\
Neutral firms (deciles 4 - 7) & $0.25^{*}$ & 1.71 & $0.28^{*}$ & 1.92 & 1.99 & 0.13 \\
Value firms (deciles 8 - 10) & $0.40^{* *}$ & 2.41 & $0.39^{* *}$ & 2.27 & 2.25 & 0.18 \\
\hline \multicolumn{7}{c}{ Panel C: Momentum } \\
\hline Loser firms (deciles 1 - 3) & 0.13 & 1.21 & 0.17 & & \\
Medium firms (deciles 4 - 7) & $0.36^{* *}$ & 2.35 & $0.39^{* *}$ & 2.46 \\
Winner firms (deciles 8 - 10) & 0.20 & 1.19 & 0.16 & 0.89 & 2.06 & 0.17 \\
\hline
\end{tabular}

For each month $t$ we sort the stocks based on size (into big and small), B/M (into value, neutral $\&$ growth) and momentum (into winner, medium \& loser). Within each of these groups, we further sort the stocks into high- and low-beta sub-groups. The Fama-French and momentum factors are taken from Agarwalla et al. (2013). The BAB factor returns for $t+1$ is calculated for each sub-group as described in Equation 5. The $4 \mathrm{~F}-\alpha$ is the alpha from the calender time regressions of the monthly excess returns on the portfolios. 
Table 5: Monthly alphas for various volatility deciles

\begin{tabular}{lccccc}
\hline Porfolio & $\begin{array}{c}\text { P1 } \\
\text { (Low Vol.) }\end{array}$ & P2 & P3 & P4 & $\begin{array}{c}\text { P5 } \\
\text { (High Vol.) }\end{array}$ \\
\hline Excess return & 0.11 & -0.28 & -0.72 & -1.25 & -2.17 \\
CAPM alpha & -0.23 & $-0.68^{*}$ & $-1.15^{* *}$ & $-1.71^{* * *}$ & $-2.67^{* * *}$ \\
Three-factor alpha & $-0.37^{*}$ & $-0.87^{* * *}$ & $-1.41^{* * *}$ & $-1.93^{* * *}$ & $-2.86^{* * *}$ \\
Four-factor alpha & -0.18 & $-0.56^{* * *}$ & $-1.11^{* * *}$ & $-1.64^{* * *}$ & $-2.63^{* * *}$ \\
$\beta$ (ex-ante) & 0.86 & 0.93 & 0.96 & 1.00 & 1.01 \\
Annualised volatility (ex-ante) & 42.64 & 57.09 & 68.52 & 83.20 & 115.86 \\
Sharpe ratio & 0.05 & -0.09 & -0.22 & -0.35 & -0.52 \\
\hline
\end{tabular}

Porftolios P1 to P5 are equally weighted portfolios constructed based on volatility quintiles. Excess returns are calculated over risk-free rate. Alpha is the intercept of regression of the portfolio excess returns over factors: (a) Market risk premium $\left(R_{M}-R_{F}\right)$ (b) $S M B$ (c) $H M L$ and (d) $W M L$. The data includes all the firms traded in the Bombay Stock Exchange over the period from January 1998 - June 2013. 
Table 6: Monthly alphas of various volatility-size quintiles

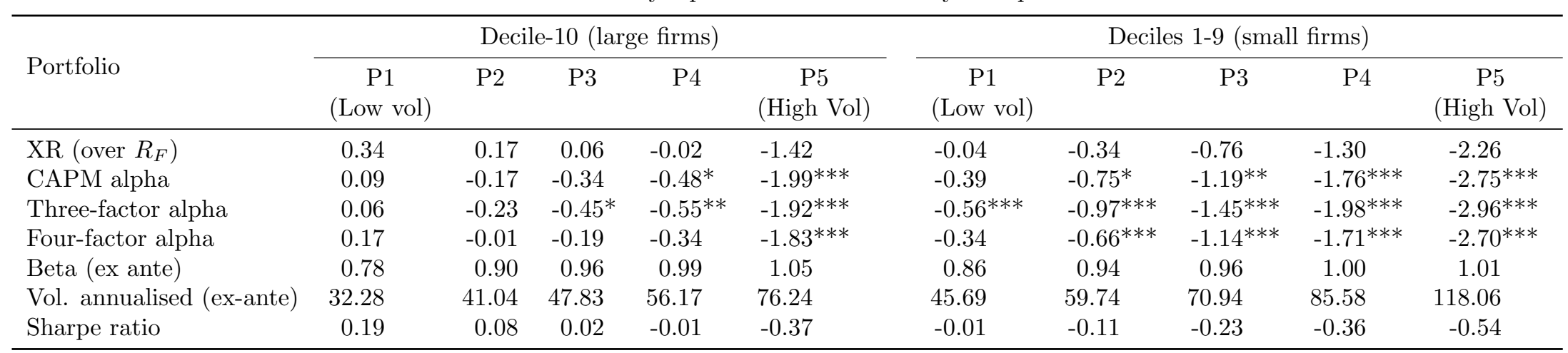

The portfolio of each month $t$ is formed by sorting the stocks first on their market capitalization (size) and then on volatility within each size group based on their estimates in the month $t-1$. The top-decile of stocks are classified as large and the remaining nine deciles are classified as small stocks. Excess returns are calculated over risk-free rate $\left(R_{f}\right)$. Alpha is the intercept of regression of the portfolio excess return over the factors: (a) Market risk premium $\left(R_{m}-R_{f}\right)(\mathrm{b}) S M B$ (c) $H M L$ and (d) $W M L$. The portfolio returns represent equally weighted returns. The returns on the four factors in the Indian market are taken from Agarwalla et al. (2013). The returns of each portfolio is equally weighted. 